\title{
Combined use of non-invasive techniques to predict pulmonary arterial pressure in chronic respiratory disease
}

\author{
J M BISHOP, M CSUKAS \\ on behalf of a working group* established by the European Office of the World Health Organisation, Copenhagen
}

\begin{abstract}
The value of non-invasive procedures for predicting pulmonary arterial pressure was investigated in 370 patients with chronic obstructive lung diseases and in 73 with fibrosing alveolitis in a combined study at nine centres in six European countries. Measurements included forced expiratory volume in one second, arterial blood gas tensions, standard electrocardiogram, radiographic dimensions of pulmonary artery, right ventricle dimensions by $\mathbf{M}$ mode echocardiography, and myocardial scintigraphy with thallium-201; and certain clinical signs were also used. No single variable was correlated closely enough to allow accurate prediction of pulmonary arterial pressure. Four methods were used to incorporate several variables into mathematical functions for predicting pulmonary arterial pressure. In patients with chronic obstructive lung disease multiple stepwise regression explained $49 \%$ of the variance in pulmonary arterial pressure but was not useful for prediction. Discriminant analysis allowed patients to be allocated to bands of pulmonary arterial pressure, as did two non-parametric procedures, in which decision trees were established using either the Kolmogoroff-Smirnoff statistic or Fisher's exact test. Patients with a pulmonary arterial pressure of $30 \mathrm{~mm} \mathrm{Hg}$ or more were identified with a sensitivity of $83 \%$ and a specificity of $91 \%$. The nonparametric tests gave better results than discriminant function. A further 54 patients were studied to validate the functions. Of these, $90 \%$ with a pulmonary arterial pressure above $20 \mathrm{~mm} \mathrm{Hg}$ were correctly identified, and $80 \%$ of those with a pulmonary arterial pressure above $29 \mathrm{~mm} \mathrm{Hg}$. Similar results were obtained in subjects with fibrosing alveolitis. These mathematical functions allow the use of combinations of non-invasive procedures to select from populations at risk of pulmonary hypertension those in whom direct measurement is required. The mathematical functions are capable of further development by incorporation of variables from newer non-invasive procedures.
\end{abstract}

\section{Introduction}

Although the occurrence of pulmonary arterial hypertension is well recognised in various forms of chronic respiratory disease, more information is needed on many aspects of the problem. The prevalence of Address for reprint requests: Professor J M Bishop, 78 Bridge End,
Warwick CV38 6PD.

*Members of the group are: JM Bishop (Birmingham), M Csukas (Budapest), H Denolin (Brussels), V Jezek (Prague), G Lamm (formerly WHO, Copenhagen), M Morpurgo (Milan), A Naszlady (Budapest), P Sadoul (Nancy), M Tartulier (Lyon), E Weitzenblum (Strasbourg), J Widimsky (Prague), J Zielinski (Warsaw).

Accepted 10 November 1988 pulmonary arterial hypertension in different diseases is unknown, and more needs to be learnt about the rate of progression over time, the extent of short term variation in pulmonary arterial mean pressure, and the long term effects of various forms of drug treatment. Cardiac catheterisation remains the method of measurement against which all others have to be judged, but it is invasive, expensive to perform, and increasingly unsuitable as more repeated measurements are required. Consequently there have been many attempts to find reliable, inexpensive, and noninvasive methods of identifying pulmonary artery hypertension.

In general, single measured variables have failed to predict pulmonary arterial pressure accurately, so 
some workers have explored the possibility that combining the results of several measurements might give a more accurate and specific prediction. Since the early study of Enson et $^{\text {al }}{ }^{1}$ there has been intermittent interest in the possibility of predicting pulmonary arterial pressure from other physiological variables. These authors determined the relation between pulmonary arterial pressure and arterial oxygen saturation $\left(\mathrm{SaO}_{2}\right)$ and arterial $\mathrm{pH}$, but the scatter about the regression was large and the precision with which pulmonary arterial pressure could be predicted was low. This finding was repeated by others. ${ }^{2-4}$ All showed that the highest correlation was with arterial oxygen saturation, but this explained less than half of the variance of pulmonary arterial pressure. The addition of other variables to the analysis produced little improvement. In the World Health Organisation multicentre study we reported ${ }^{5}$ the largest series of patients with chronic obstructive lung disease, and again $\mathrm{SaO}_{2}$ alone explained only $42 \%$ of the variance of pulmonary arterial pressure, packed cell volume and forced expiratory volume in one second $\left(\mathrm{FEV}_{1}\right)$ explaining only a further $2 \%$.

Attention began to turn towards the use of other relatively non-invasive measurements, alone or in combination with blood gas values and results of other pulmonary function tests. Some of these studies tried to predict the value of pulmonary arterial pressure while others sought to diagnose the presence or absence of pulmonary arterial hypertension. Tartulier et al ${ }^{6}$ followed the latter approach and in a study of 43 patients with chronic obstructive lung disease were able to categorise patients accurately using a combination of arterial oxygen tension $\left(\mathrm{PaO}_{2}\right)$ and the electrocardiogram (ECG) or vectorcardiogram. Evers and Liehs ${ }^{7}$ studied 372 patients with chronic obstructive lung disease and used a linear discriminant analysis with nine variables derived from pulmonary function tests and measurements of pulmonary arterial diameter on a chest radiograph. The discriminant function allowed the correct identification of $79 \%$ of the patients with pulmonary hypertension in a new series. Keller et $a l^{8}$ studied 89 patients with chronic obstructive lung disease and by stepwise linear regression analysis found it possible to explain $60 \%$ of the variance of pulmonary arterial pressure, using $\mathrm{PaO}_{2}$, $\mathrm{PaCO}_{2}$, and the diameter of the right descending branch of the pulmonary artery. Most recently OswaldMammosser et al $^{9}$ investigated the sensitivity of variables singly and in combination for identifying the presence of pulmonary arterial hypertension in 63 patients with chronic obstructive lung disease and found that combinations always gave better results. With stepwise regression it was possible to account for only $43 \%$ of the total variance.

It may be concluded that no single non-invasive procedure allows prediction of the presence of pulmonary arterial hypertension or the level of pulmonary arterial pressure with a sufficient degree of reliability to be of value clinically. Combinations of non-invasive measurements allow prediction of the presence of pulmonary arterial hypertension with satisfactory probability, but the precise level of pulmonary arterial pressure cannot be predicted with sufficient accuracy to be useful. Some of the newer techniques, including Doppler flow measurements and two dimensional echocardiography, show greater promise but it still seems unlikely that any of them used alone will make it necessary to alter these conclusions.

In the present study we have extended previous approaches by using combinations of measurements and some newer statistical and mathematical methods, and have applied them to a larger collection of new data than has been available to earlier workers. The three important characteristics of the study are: $(a)$ it uses only those non-invasive methods which were available in all of the participating centres at the time when the study started in 1978 , and which at that time were considered likely to prove useful; $(b)$ it uses various statistical methods, some non-parametric, in an attempt to find the most effective way of utilising the results of the non-invasive measurements; $(c)$ the patients studied are from two diagnostic groups and the predictive values of the measurements in the two groups are compared.

\section{Methods}

\section{SELECTION OF PATIENTS}

The centres in the study were Brussels, Budapest, Lyons, Milan, Nancy, Prague, Strasbourg, and Warsaw. Patients aged 20-65 years with one of two diagnoses were recruited.

Chronic obstructive lung disease Patients had to have either chronic bronchitis, characterised by cough and sputum for at least three consecutive months for each of two consecutive years, or emphysema, characterised by dyspnoea with radiological evidence of emphysema. Both groups had to have functional evidence of airways obstruction $\left(\mathrm{FEV}_{\mathrm{1}} / \mathrm{FVC}<55 \%\right)$. Fibrosing alveolitis This was defined by restrictive changes with increased elastic recoil, either caused by exogenous factors or of unknown origin. The diagnosis was made radiologically and on the basis of functional changes, including decreased vital capacity, transfer factor for carbon monoxide, and static compliance, without features of airways obstruction.

Patients were excluded if they had kyphoscoliosis, past thoracic surgery, pneumothorax present or past, asthma at time of study, systemic hypertension (under treatment or diastolic pressure $>105 \mathrm{~mm} \mathrm{Hg}$ ), 
rheumatic or congenital heart disease, a history of myocardial infarction or angina, pulmonary infection within the last three months, pulmonary embolism or infarction within the last month, pronounced obesity (Broca index $>120 \%$ ) or other serious disease.

It was intended that the selection should provide patients with pulmonary arterial pressures ranging from normal to substantially raised. In the event $45 \%$ of the patients had a pulmonary arterial mean pressure below $20 \mathrm{~mm} \mathrm{Hg}, 31 \%$ in the range $20-29 \mathrm{~mm} \mathrm{Hg}$, and $24 \%$ of $30 \mathrm{~mm} \mathrm{Hg}$ or more. Results of the noninvasive measurements were not available at the time of selection.

The patients were chosen from those attending the centres taking part in the study. As the special interests of these centres varied, and did not in all cases include the full range of respiratory disease, the proportion of patients in the two diagnostic groups varied between centres. The patients studied were therefore a selected sample, chosen to facilitate the study of the relation between certain non-invasive measurements and the level of pulmonary arterial pressure. Because of the way the sample was drawn the results do not define the frequency distribution of levels of pulmonary arterial pressure in a population of patients with any of the stated diagnoses.

An additional group of patients with thromboembolic lung disease was studied simultaneously by identical methods and the results will be reported separately.

The total number of patients studied was $370-297$ with chronic obstructive lung disease and 73 with fibrosing alveolitis. After the main part of the study on 370 patients was completed a further 54 patients with chronic obstructive lung disease were examined to test the validity of the derived functions prospectively. The technical methods and procedures were the same as for the earlier part of the investigation.

\section{PROTOCOL AND MEASUREMENTS}

Measurements were made after it had been established that the patient was in a steady clinical state, with a stable body weight and no history of increased symptoms, cardiac failure, or respiratory infection during the previous month.

Data concerning personal details, past history, present symptoms, and findings of the physical examination were collected. A set of non-invasive measurements was carried out on each patient (see below) and measurement of pulmonary arterial pressure at cardiac catheterisation. No fixed order was specified, but the measurements had to be completed within 14 days.

The following procedures were attempted in each patient (obligatory measurements): 12 lead electrocardiography; $M$ mode echocardiography; radio- graphy of chest; recording of forced expiratory spirogram; arterial blood gas tensions and $\mathrm{pH}$; haemoglobin concentration and packed cell volume.

Other non-invasive procedures were optional as they were available in only a few centres - for example, myocardial scintigraphy using thallium-201. ${ }^{10}$ Other methods proved to have little diagnostic value or were technically unsatisfactory. These procedures, the results of which were not used in the analysis but have been described elsewhere, included precordial mechanocardiography, ${ }^{11}$ measurement of orthostatic variation in transfer factor for carbon monoxide, ${ }^{12}$ perfusion scans of the lung, ${ }^{13}$ vectorcardiography, ${ }^{14}$ and measurements of airways resistance and lung compliance.

\section{TECHNICAL PROCEDURES}

The methods were in most cases in regular use in the participating centres. The equipment was not identical in all centres, but standard procedures for measurement were laid down. These were as follows: Cardiac catheterisation This was performed with the patient supine. Intravascular pressures were recorded in relation to a zero point $5 \mathrm{~cm}$ below the sternal angle. Mean pressures were determined by electrical integration over at least three respiratory cycles. Cardiac output was measured by the direct Fick or thermodilution method.

Arterial blood gas tensions These were measured by standard methods using covered electrodes, with frequent calibration. Haemoglobin concentration and packed cell volume were measured by the usual methods.

Forced expiratory volume in one second was measured from a spirogram, the best of three attempts being used. Forced vital capacity was measured in the same way, but slow vital capacity was substituted if it gave a larger value.

The dimensions of the pulmonary artery were measured from standard posteroanterior radiographs of the chest taken with a source to film distance of $2 \mathrm{~m}$. The transhilar distance was measured as described by Hicken et al. ${ }^{15}$ The diameter of the descending branch of the right lower lobe artery (PAD) was measured as described by Morbelli et al. ${ }^{16}$ In some instances tomography or xerotomography was used to help in identifying the borders of the pulmonary artery. A sample of the radiographs was sent to one centre and the measurements were repeated to ensure consistency.

$M$ mode echocardiograph This was recorded by the precordial or subxiphoid approach. Measurements were made of the thickness of the wall of the right and left ventricles in both systole and diastole and of the diameter of the right and left ventricular cavities in diastole. Recordings were also attempted of the 
movements of the pulmonary valve to allow measurement of the opening slope and the "a" dip (DEPTHA). The pre-ejection period (PEP) was measured where possible. Difficulty was experienced frequently in the patients with chronic obstructive lung disease owing to the hyperinflated lung. Successful recordings of pulmonary valve movement were obtained in only $25 \%$ of the patients studied, but ventricular recordings were obtained in $68 \%$. Some of the tracings were again measured in one centre, to ensure consistency in the method of measuring the traces.

Electrocardiography This used the standard 12 leads plus V4R. A random sample of tracings was remeasured at one centre, to check that there was no intercentre variation.

Myocardial scintigaphy This used thallium-201 and was performed as described by Weitzenblum et al. ${ }^{10}$ The extent of any image formed by the wall of the right ventricle was graded from 0 to 3 .

\section{CONSTRUCTION OF DATA SETS}

All data were screened according to preset limits, and by inspection. All results that were outside limits or appeared questionable or inconsistent with the diagnosis were referred back to the principal investigator for confirmation.

The obligatory investigations were completed in each patient, with the exception of the echocardiogram in some patients with chronic obstructive lung disease, as already noted. In a few instances it was not possible to measure the dimensions of the pulmonary artery on the radiograph, especially in patients with fibrosing alveolitis, because the borders were indistinct and in a few patients there were no measurable $\mathbf{S}$ waves on right sided leads of the electrocardiogram. The only optional measurement performed in sufficient patients to be useful in the analysis was right ventricular myocardial scintigraphy using thallium.

In addition to the continuous numerical variables, a few discrete variables, including ones based on clinical signs and historical features, were used in parts of the analysis. These were the presence or absence of the following (abbreviations in parentheses):

signs of raised pressure in neck veins (NECK VEINS) enlarged liver on palpation (LIVER)

past history of cardiac or combined cardiac and respiratory failure (PAST HISTORY)

negative $T$ wave in leads V1-3 (NEGTWAVE)

ST-T depression in V1 and V2 (STTDEP)

right bundle branch block of whatever degree (RBBB)

Table 1 Mean values and standard deviations of variables for three categories of pulmonary arterial pressure (PAP, in $\mathrm{mm} \mathrm{Hg}$ ) and correlation coefficients between each variable and pulmonary arterial mean pressure in patients with chronic obstructive lung disease

\begin{tabular}{|c|c|c|c|c|c|c|c|c|c|c|c|c|}
\hline \multirow[b]{2}{*}{ Variable } & \multirow[b]{2}{*}{ Abbreviation } & \multirow[b]{2}{*}{ Unit } & \multicolumn{3}{|c|}{$P A P \leqq 19$} & \multicolumn{3}{|c|}{$20 \leqq P A P \leqq 29$} & \multicolumn{3}{|c|}{$P A P \geqq 30$} & \multirow{2}{*}{$\begin{array}{l}\text { Correlation } \\
\text { coefficient } \\
(\boldsymbol{r})\end{array}$} \\
\hline & & & $n$ & Mean & $S D$ & $n$ & Mean & $S D$ & $n$ & Mean & $S D$ & \\
\hline $\begin{array}{l}\text { Heart rate } \\
\text { R wave V1 } \\
\text { R wave V5 } \\
\text { R wave AVR } \\
\text { S wave V1 } \\
\text { S wave V5 } \\
\text { S wave D1 } \\
\text { S wave D2 } \\
\text { Q wave VR } \\
\text { Max height P2 or P3 } \\
\text { Intrinsicoid deflection V1 } \\
\text { RV wall thickness-diastolic } \\
\text { RV cavity-diastolic } \\
\text { Opening slope } \\
\text { Diastolic slope } \\
\text { Transhilar distance } \\
\text { Diameter RLL artery } \\
\text { Vital capacity } \\
\text { Forced expiratory volume in } 1 \\
\text { FEV/FVC } \\
\text { Total lung capacity } \\
\text { Arterial O tension } \\
\text { Arterial CO, tension } \\
\text { Arterial pH } \\
\text { Haemoglobin concentration } \\
\text { Packed cell volume }\end{array}$ & $\begin{array}{l}\text { HRATE* } \\
\text { RWAVE V1* } \\
\text { RWAVE V5* } \\
\text { RWAVE AVR* } \\
\text { SWAVE V1* } \\
\text { SWAVE V5* } \\
\text { SWAVE D1* } \\
\text { SWAVE D2* } \\
\text { QWAVE* } \\
\text { MaXP2P3* } \\
\text { IDV1 } \\
\text { RVWDIAS } \\
\text { RVDC } \\
\text { OPSLOPE } \\
\text { DSLOPE } \\
\text { THD* } \\
\text { PAD } \\
\text { VC* } \\
\text { SFEV }{ }^{*} \\
\text { TIFF* } \\
\text { TLC } \\
\text { PO }{ }^{*} \\
\text { PCO } \\
\text { PH* } \\
\text { Hb* } \\
\text { PCV* }\end{array}$ & $\begin{array}{l}\mathrm{min}^{-1} \\
\mathrm{~mm} \\
\mathrm{~mm} \\
\mathrm{~mm} \\
\mathrm{~mm} \\
\mathrm{~mm} \\
\mathrm{~mm} \\
\mathrm{~mm} \\
\mathrm{~mm} \\
\mathrm{msec} \\
\mathrm{mm} \\
\mathrm{mm} \\
\mathrm{mm} / \mathrm{s} \\
\mathrm{mm} / \mathrm{s} \\
\mathrm{mm} \\
\mathrm{mm} \\
\mathrm{cl} \\
\mathrm{cl} \\
\% \\
\mathrm{cl} \\
\mathrm{mm} \mathrm{Hg} \\
\mathrm{mm} \mathrm{Hg} \\
\mathrm{g} / \mathrm{l} \\
\%\end{array}$ & $\begin{array}{r}116 \\
116 \\
116 \\
116 \\
116 \\
116 \\
113 \\
113 \\
116 \\
116 \\
100 \\
52 \\
71 \\
9 \\
22 \\
111 \\
98 \\
116 \\
116 \\
116 \\
94 \\
116 \\
116 \\
113 \\
115 \\
114\end{array}$ & $\begin{array}{c}79 \cdot 2 \\
1 \cdot 7 \\
10 \cdot 2 \\
0.9 \\
5 \cdot 9 \\
3 \cdot 6 \\
1 \cdot 2 \\
1 \cdot 5 \\
3 \cdot 6 \\
1.6 \\
23 \cdot 3 \\
6 \cdot 0 \\
22 \cdot 1 \\
374 \\
34 \cdot 3 \\
106 \cdot 7 \\
15.4 \\
315 \\
136 \cdot 7 \\
42 \cdot 5 \\
665 \\
66 \cdot 8 \\
39.2 \\
412 \\
146 \\
45 \cdot 4\end{array}$ & $\begin{array}{c}16 \cdot 2 \\
1 \cdot 8 \\
5 \cdot 4 \\
1 \cdot 0 \\
3 \cdot 1 \\
2 \cdot 6 \\
2 \cdot 0 \\
1 \cdot 5 \\
2 \cdot 3 \\
0 \cdot 7 \\
16 \cdot 9 \\
1 \cdot 9 \\
7 \cdot 3 \\
145 \\
28 \cdot 1 \\
14 \cdot 2 \\
3 \cdot 8 \\
92 \\
60 \cdot 4 \\
12 \cdot 1 \\
154 \\
10 \cdot 4 \\
6 \cdot 0 \\
37 \\
17 \\
6 \cdot 1\end{array}$ & $\begin{array}{r}115 \\
115 \\
115 \\
115 \\
115 \\
115 \\
112 \\
112 \\
115 \\
115 \\
90 \\
60 \\
81 \\
21 \\
26 \\
111 \\
103 \\
115 \\
115 \\
114 \\
92 \\
115 \\
115 \\
112 \\
115 \\
110\end{array}$ & $\begin{array}{c}85 \cdot 9 \\
2 \cdot 3 \\
9 \cdot 3 \\
1 \cdot 3 \\
6 \cdot 1 \\
5 \cdot 1 \\
1 \cdot 7 \\
1 \cdot 9 \\
3 \cdot 3 \\
1 \cdot 9 \\
24 \cdot 9 \\
6 \cdot 3 \\
24 \cdot 7 \\
397 \\
21 \cdot 0 \\
111 \cdot 6 \\
16 \cdot 3 \\
269 \\
104 \cdot 5 \\
38 \cdot 1 \\
643 \\
61 \cdot 1 \\
43 \cdot 9 \\
400 \\
152 \\
48 \cdot 4\end{array}$ & $\begin{array}{c}16 \cdot 7 \\
3 \cdot 6 \\
5 \cdot 1 \\
1 \cdot 5 \\
4 \cdot 3 \\
4 \cdot 0 \\
1 \cdot 6 \\
2 \cdot 1 \\
2 \cdot 4 \\
0 \cdot 8 \\
19 \cdot 4 \\
2.4 \\
7 \cdot 6 \\
134 \\
10.6 \\
11 \cdot 5 \\
4.4 \\
76 \\
47 \cdot 7 \\
12 \cdot 3 \\
135 \\
9.9 \\
8.9 \\
37 \\
22 \\
8.5\end{array}$ & $\begin{array}{l}66 \\
66 \\
66 \\
66 \\
66 \\
66 \\
65 \\
65 \\
66 \\
66 \\
56 \\
30 \\
51 \\
25 \\
27 \\
60 \\
60 \\
66 \\
66 \\
66 \\
42 \\
66 \\
66 \\
64 \\
66 \\
65\end{array}$ & $\begin{array}{c}88 \cdot 0 \\
3 \cdot 1 \\
7 \cdot 8 \\
2 \cdot 1 \\
4 \cdot 0 \\
7 \cdot 4 \\
3 \cdot 2 \\
2 \cdot 4 \\
2 \cdot 8 \\
2 \cdot 0 \\
38 \cdot 3 \\
7 \cdot 3 \\
30 \cdot 2 \\
427 \\
21 \cdot 6 \\
115 \cdot 6 \\
19 \cdot 7 \\
251 \\
96 \cdot 0 \\
37 \cdot 7 \\
606 \\
53 \cdot 9 \\
47 \cdot 6 \\
397 \\
159 \\
51 \cdot 5\end{array}$ & $\begin{array}{c}15 \cdot 2 \\
3 \cdot 2 \\
4 \cdot 6 \\
1 \cdot 8 \\
3 \cdot 9 \\
4 \cdot 8 \\
2 \cdot 3 \\
2 \cdot 5 \\
2.4 \\
0 \cdot 9 \\
22 \cdot 4 \\
2.0 \\
10.6 \\
130 \\
18 \cdot 8 \\
14.5 \\
5.0 \\
75 \\
43.6 \\
10 \cdot 6 \\
169 \\
10.7 \\
8 \cdot 7 \\
39 \\
20 \\
9.3\end{array}$ & $\begin{array}{c}0.21 \\
0.23 \\
-0.16 \\
0.33 \\
-0.20 \\
0.37 \\
0.39 \\
0.20 \\
-0.10 \dagger \\
0.20 \\
0.31 \\
0.22 \\
0.42 \\
0.13 \dagger \\
-0.20 \dagger \\
0.28 \\
0.41 \\
-0.29 \\
-0.28 \\
-0.13 \\
-0.18 \\
-0.45 \\
0.38 \\
-0.22 \\
0.23 \\
0.28\end{array}$ \\
\hline
\end{tabular}

*Variables which with PAP comprise first data set (see text).

†Does not differ significantly from zero.

$\mp$ D leads are standard limb leads.

$1 \mathrm{~mm} \mathrm{Hg} \approx 0.133 \mathrm{kPa}$. 
any degree of thallium uptake by right ventricular myocardium (RVWIM).

The patients were divided into three categories according to their pulmonary arterial presure. The categories were $19 \mathrm{~mm} \mathrm{Hg}$ or less, 20 to $29 \mathrm{~mm} \mathrm{Hg}$, and $30 \mathrm{~mm} \mathrm{Hg}$ or more. From the variables measured those that showed substantial differences in mean values between the three pulmonary artery pressure categories were selected. The use of several data sets was necessary because of missing items.

For patients with chronic obstructive lung disease the following four data sets were used:

The first set comprised the results of the obligatory measurements listed above, excluding those derived from echocardiography. The variables and their abbreviations are shown in table 1 . There were 20 variables and 263 patients.

The second set consisted of the variables in the first set together with three additional variables (intrinsicoid deflection V1 (IDV 1), pulmonary arterial diameter (PAD) and total lung capacity (TLC)), and six discrete variables (NECK VEINS, LIVER, PAST HISTORY, NEGTWAVE, STTDEP, and RBBB). This was the largest and most comprehensive data set, consisting of 29 variables. There were 129 patients.

The third set consisted of the continuous variables in the second set, plus two variables from the echocardiogram (RVWDIAS and RVDC). There were 25 variables and 86 patients.

The fourth set consisted of the variables in the third set with the addition of the discrete variable for the presence or absence of a right ventricular image on the scintigram (RVWIM). There were 26 variables and 70 patients.

For the patients with fibrosing alveolitis the following two data sets were used:

The first set consisted of the continuous variables measured in most patients, excluding any derived from chest radiography or echocardiography. There were 14 variables, indicated in table 4 (with abbreviations), and 69 patients.

The second set comprised the variables in the first set together with three from the echocardiogram (RVDC, DEPTHA, and PEP) and one discrete variable (LIVER). There were 18 variables and 35 patients.

\section{DATA ANALYSIS}

The following methods were used:

Regression analysis Multiple stepwise regression analysis was performed using the methods of the BMDP Statistical Software (University of California at Los Angeles, 1981). The results were used to predict the numerical value of pulmonary arterial pressure (the results of the other procedures are used to put the patients into one of the pulmonary arterial pressure categories).
Discriminant analysis Linear discriminant analysis was used to divide the patients into two categories (appendix).

Non-parametric decision procedures A fuller description of these is provided in the appendix. The first is based on the Kolmogoroff-Smirnoff statistic ${ }^{17-19}$ and divides the population into two parts at a cutting point. The second ${ }^{22}$ uses Fisher's exact test ${ }^{23}$ to select the variables to be used, the order in which they are to be used, and the cutting point. The population is divided into three categories in a two stage procedure. After completion of the first stage all the remaining members of the population are used in the second stage.

The effectiveness of these procedures has been judged in terms of sensitivity and specificity. The former is a measure of the ability of the test to place all individuals in the population studied who have the defined characteristic correctly-that is, within a particular pulmonary arterial pressure category. It is estimated as the proportion of true positives correctly placed. Specificity is a measure of the effectiveness of the test in selecting only those individuals who truly fall within a category without selecting others who do not. It is estimated as the proportion of true negatives correctly placed.

\section{Results}

The two diagnostic groups are considered separately.

\section{CHRONIC OBSTRUCTIVE LUNG DISEASE}

Table 1 gives the mean values and standard deviations of the variables with correlation coefficients for individual variables and pulmonary arterial pressures. This ranged from 6 to $62 \mathrm{~mm} \mathrm{Hg}$, with a mean of 23.4 (SD 9.8) and a median of 21. The distribution of pulmonary arterial pressures was skewed and the objective of obtaining an even spread of values was not fully achieved as only $22 \%$ of values were $30 \mathrm{~mm} \mathrm{Hg}$ or greater.

Stepwise regression was performed for each data set. There was no "centre effect," indicating that there was no systematic difference between centres in measuring pulmonary artery pressure.

By using the first set (table 2) it was possible to explain $34 \%$ of the variance in pulmonary artery pressure values. By using the second set $44 \%$ of the variance of pulmonary artery pressure was explained by six variables, of which four were continuous and two discrete. The order in which these variables entered the regression equation (table 2) was: negati ve $\mathrm{T}$ wave in $\mathrm{V} 1$, pulmonary arterial diameter, vital capacity, enlarged liver, maximum $P$ wave height, and arterial $\mathrm{pH}$.

Analysis of the third data set allowed $49 \%$ of the 
Table 2 Results of stepwise regression analysis using two data sets in patients with chronic obsrtructive lung disease

\begin{tabular}{|c|c|c|c|c|c|}
\hline \multicolumn{3}{|l|}{$\operatorname{SETI}(n=263)$} & \multicolumn{3}{|l|}{$\operatorname{SETII}(n=129)$} \\
\hline Entered variables & $R^{2} \%$ & $\begin{array}{l}\text { Coefficient of regression } \\
\text { equation }(S E)\end{array}$ & Entered variables & $R^{2} \%$ & $\begin{array}{l}\text { Coefficient of regression } \\
\text { equation }(S E)\end{array}$ \\
\hline $\begin{array}{l}\mathrm{Po}_{2} \\
\mathrm{~S} \text { wave V5 } \\
\text { THD } \\
\text { vC } \\
\text { S wave S1 } \\
\text { Intercept }\end{array}$ & $\begin{array}{l}19.4 \\
26.8 \\
30.0 \\
32.3 \\
34.0\end{array}$ & $\begin{array}{r}-0.230(0.049) \\
0.440(0.015) \\
0.137(0.038) \\
-0.020(0.006) \\
0.768(0.303) \\
24.237\end{array}$ & $\begin{array}{l}\text { Neg T wave } \\
\text { PAD } \\
\text { VC } \\
\text { LIVER } \\
\text { Max P2 P3 } \\
\text { pH } \\
\text { Intercept }\end{array}$ & $\begin{array}{l}14 \cdot 7 \\
23 \cdot 2 \\
30 \cdot 6 \\
35 \cdot 5 \\
40 \cdot 4 \\
44 \cdot 3\end{array}$ & $\begin{array}{r}5.486(1.491) \\
0.483(0.122) \\
-0.021(0.008) \\
4.420(1.299) \\
2.451(0.756) \\
-0.014(0.015) \\
31.576\end{array}$ \\
\hline
\end{tabular}

variance to be explained by six variables, which comprised two echocardiographic measurements (right ventricular wall and cavity) and two radiographic measurements (pulmonary arterial diameter and transhilar distance), together with packed cell volume and vital capacity. This was based on less than a third of the total patients, however, and so may be less reliable. Use of the first and fourth data sets gave less satisfactory results.

\section{Linear discriminant analysis}

The procedure was used first to predict whether pulmonary arterial pressure was $20 \mathrm{~mm} \mathrm{Hg}$ or more or less than $20 \mathrm{~mm} \mathrm{Hg}$, and then for dividing points at 25 and $30 \mathrm{~mm} \mathrm{Hg}$. The second data set was found to give the best result. The variables used at the dividing point of $20 \mathrm{~mm} \mathrm{Hg}$ were presence or absence of negative $\mathrm{T}$ wave, $\mathrm{FEV}_{1}$, and packed cell volume. At the dividing point of $25 \mathrm{~mm} \mathrm{Hg} \mathrm{P} \mathrm{wave} \mathrm{height,} \mathrm{presence} \mathrm{or} \mathrm{absence}$ of negative $T$ wave in V1-2, pulmonary arterial diameter, and $\mathrm{FEV}_{1}$ were used. At the dividing point of $30 \mathrm{~mm} \mathrm{Hg}$ the variables were presence or absence of enlarged liver, $R$ wave in aVR, and negative $T$ wave, and pulmonary arterial diameter. At the three dividing points sensitivity ranged from $80 \%$ to $51 \%$, and specificity from $60 \%$ to $94 \%$. A multistage approach gave a function that was more sensitive but less specific.

\section{Non-parametric procedure using Kolmogoroff-Smirnoff statistic}

The decision procedure based on this statistic was carried out for the same categories of pulmonary arterial pressure as the discriminant function. The data used were from the second set. The results (figs 1 and 2) are similar to those from the discriminant function analysis. Sensitivity ranged from $66 \%$ to $74 \%$ for the three pulmonary arterial pressure classifications, with corresponding specificity ranging from $75 \%$ to $85 \%$.

\section{Non-parametric procedure using Fisher's exact test} The decision procedure in stage 1 used 11 variables in sequence (figs 3 and 4). It selected those patients in whom the pulmonary artery pressure was $30 \mathrm{~mm} \mathrm{Hg}$ or greater with a sensitivity of $83 \%$ and a specificity of $91 \%$. In stage 2 (fig 4 ) there were again 11 steps, some of which used the same variable for a second time in the sequence. This procedure selected patients whose pulmonary artery pressure was $20 \mathrm{~mm} \mathrm{Hg}$ or greater from the population remaining after those selected as having a pulmonary artery pressure of $30 \mathrm{~mm} \mathrm{Hg}$ or greater had been excluded. The sensitivity was $91 \%$ and specificity $55 \%$.

\section{Testing the derived functions}

The data from a further 54 patients with chronic obstructive lung disease studied after the main investigation were entered into the derived functions and the predicted values and classifications were compared with the directly measured values for pulmonary artery pressure.

The results presented in table 3 show the percentage of patients correctly placed in one of the three pulmonary artery pressure categories. Regression analysis correctly placed $59 \cdot 2 \%$, the non-parametric

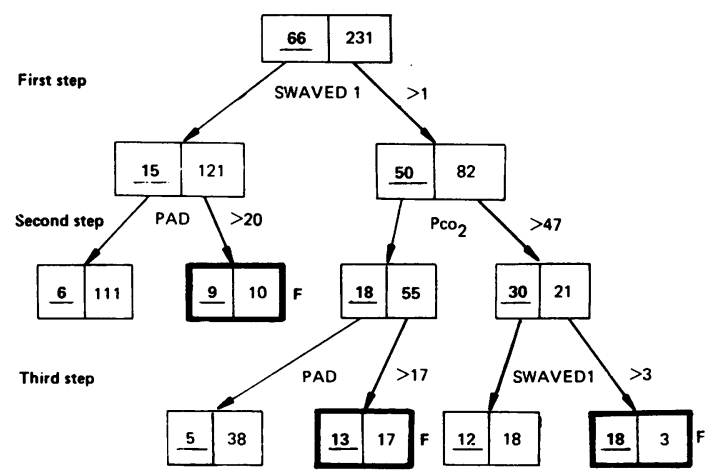

Fig 1 Non-parametric procedure using the KolmogoroffSmirnoff statistic in patients with chronic obstructive lung disease. The groups are pulmonary arterial pressure (PAP) $\leqslant 29$ and $P A P \geqslant 30 \mathrm{~mm} \mathrm{Hg}$. Underlined numbers indicate patients with measured $P A P \geqslant 30 \mathrm{~mm} \mathrm{Hg}$, and rectangles with thick lines and the letter $F$ indicate those classified as having PAP $\geqslant 30 \mathrm{~mm} \mathrm{Hg}$. 


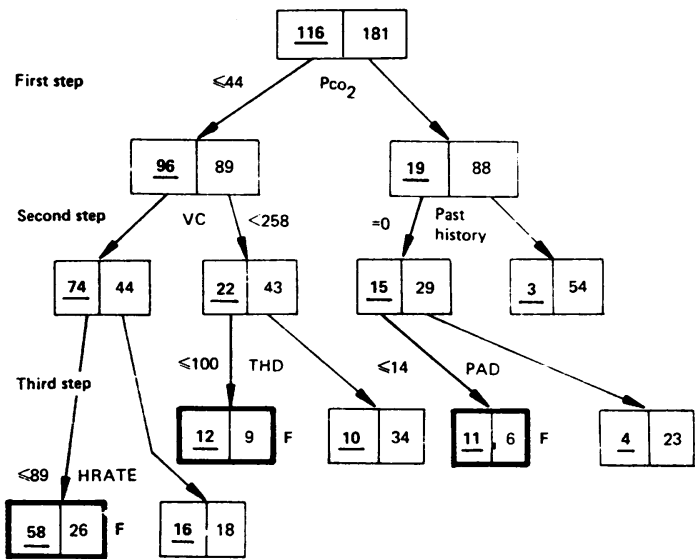

Fig 2 Non-parametric procedure using the KolmogoroffSmirnoff statistic in patients with chronic obstructive lung disease. The groups are pulmonary arterial pressure (PAP) $\leqslant 19$ and $P A P \geqslant 20 \mathrm{~mm} \mathrm{Hg}$. Underlined numbers indicate patients with measured $P A P \leqslant 19 \mathrm{~mm} \mathrm{Hg}$, and rectangles with thick lines and the letter $F$ indicate those classified as having PAP $\leqslant 19 \mathrm{~mm} \mathrm{Hg}$.

Kolmogoroff-Smirnoff method $60 \cdot 4 \%$, and the nonparametric method using Fisher's exact test $48 \cdot 2 \%$. All methods placed a proportion of patients in a falsely high pulmonary artery pressure category, the proportion ranging from $28.3 \%$ to $44 \cdot 4 \%$. The proportion placed in a falsely low category ranged from $7 \cdot 4 \%$ to $11 \cdot 3 \%$.

To express this in another way, one relevant to the use of the procedures to screen for the presence of pulmonary hypertension, three of the four methods were able to correctly identify around $80 \%$ of the patients who had a pulmonary artery pressure above $30 \mathrm{~mm} \mathrm{Hg}$ and around $90 \%$ of those whose pulmonary artery pressure was $20 \mathrm{~mm} \mathrm{Hg}$ or more. Discriminant analysis proved slightly less effective than the other methods.

\section{DIFFUSE FIBROSING ALVEOLITIS}

The mean values and standard deviations of the variables, with the correlation coefficients between values for individual variables and pulmonary arterial pressure are given in table 4. Pulmonary arterial pressure ranged from 6 to $53 \mathrm{~mm} \mathrm{Hg}$, with a mean of 23.5 (SD 10.9) and a median value of 21 , and again the distribution of values was skewed.

Stepwise regression was performed on the first data set for 69 patients (table 5). Four variables (packed cell volume, MAXP2P3, $\mathrm{PO}_{2}$, and RWAVEv1) explained $56 \%$ of the variance in pulmonary arterial pressure. Using the second data set made it possible to explain $78 \%$ of the variance, but there were only 35 patients in the set. The variables used were packed cell volume, haemoglobin concentration, depth of the " $a$ " dip in the pulmonary valve echo, diastolic diameter of right ventricle, and intrinsicoid deflection in V1.

Linear discriminant analysis was performed with the first data set at dividing points of 20 and $30 \mathrm{~mm} \mathrm{Hg}$. The first function used only one variable, SWAVEV, and had a sensitivity of $55 \%$ and a specificity of $72 \%$. The second, using heart rate and $\mathrm{PCO}_{2}$, had a sensitivity of $87 \%$ and a specificity of $77 \%$.

Non-parametric procedure using Kolmogoroff-Smirnoff statistic This was performed for the same pulmonary arterial pressure categories as for discriminant analysis and the results were similar for the two methods. For patients with a pulmonary arterial pressure under $20 \mathrm{~mm} \mathrm{Hg}$ sensitivity was $50 \%$ and specificity $97 \%$. For patients classified for a pulmonary arterial pressure of $30 \mathrm{~mm} \mathrm{Hg}$ or more sensitivity was $100 \%$ and specificity $63 \%$. The number of cases was relatively small, however, and these results are

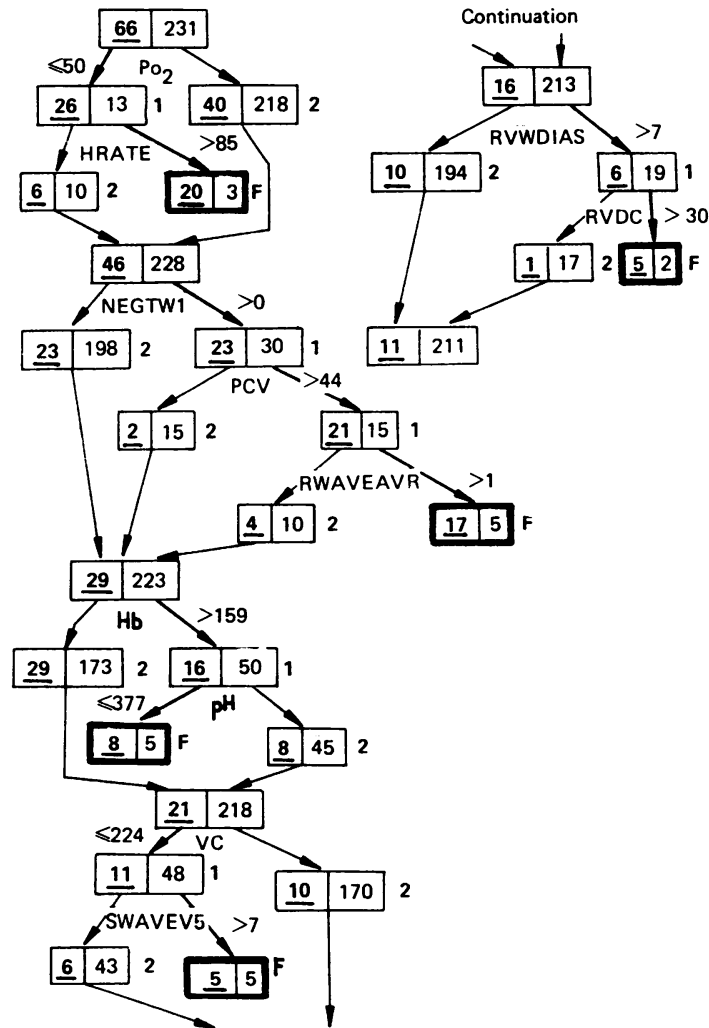

Fig 3 Decision graph using Fisher's exact test for patients with chronic obstructive lung disease: first stage. The groups are pulmonary arterial pressure $(P A P) \leqslant 29$ and $P A P$ $\geqslant 30 \mathrm{~mm} \mathrm{Hg}$. Underlined numbers indicate patients with measured $P A P \geqslant 30 \mathrm{~mm} \mathrm{Hg}$, and rectangles with thick lines and the letter $F$ indicate those classified as having $P A P \geqslant 30$ $\mathbf{m m ~} \mathbf{H g}$. 


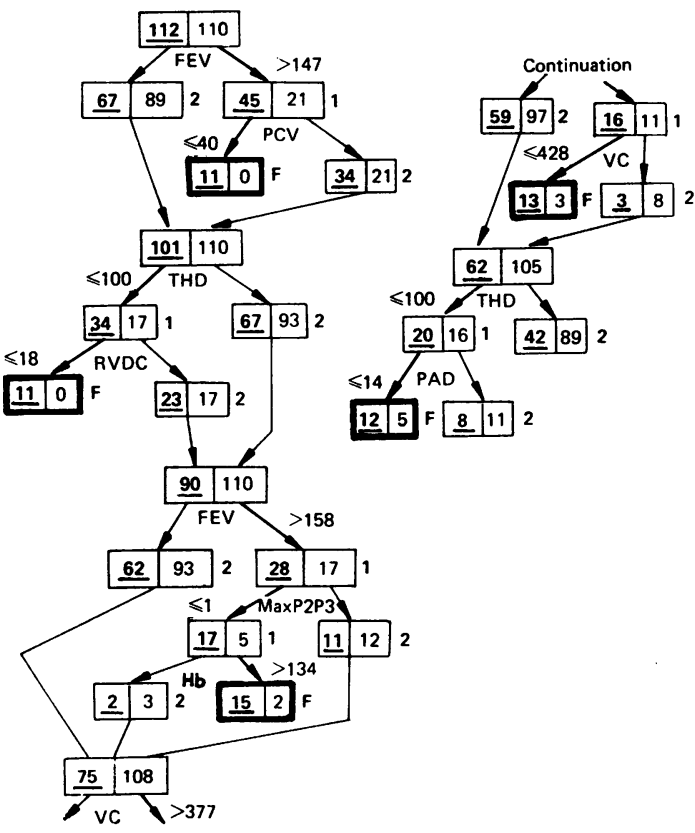

Fig 4 Decision graph using Fisher's exact test for patients with chronic obstructive lung disease: second stage. The groups are pulmonary arterial pressure $(P A P) \leqslant 19$ and $P A P \geqslant 20 \mathrm{~mm} \mathrm{Hg}$. Underlined numbers indicate patients with measured $P A P \leqslant 19 \mathrm{~mm} \mathrm{Hg}$, and rectangles with thick lines and the letter $F$ indicate those classified as having PAP $\leqslant 19 \mathrm{~mm} \mathrm{Hg}$.

probably not different from those using discriminant analysis.

Non-parametric procedure using FET With this procedure patients were divided first into those with a pulmonary arterial pressure of $30 \mathrm{~mm} \mathrm{Hg}$ or greater and those below $30 \mathrm{~mm} \mathrm{Hg}$. The sequence used five variables (MAXP2P3, $\mathrm{PCO}_{2}$, DEPTHA, LIVER, and $\mathrm{PO}_{2}$ ) and achieved a sensitivity of $85 \%$ and specificity $94 \%$. In the second stage subjects with a pulmonary arterial pressure of $19 \mathrm{~mm} \mathrm{Hg}$ or less were separated from those with a pressure of $20-29 \mathrm{~mm} \mathrm{Hg}$, those already classified as belonging to the higher pulmonary arterial pressure group being excluded. The classification used six variables (HGB, RWAVEAVR, $\mathrm{PO}_{2}, \mathrm{PEP}, \mathrm{PO}_{20} \overrightarrow{\overrightarrow{2}}$ (second time), and $\mathrm{FEV}_{1}$ ). The sensitivity was $94 \%$ and the specificity $77 \%$.

\section{Discussion}

In a multicentrre study in several countries there will always be difficulties in maintaining consistency in the $\vec{\circ}$ procedures and methods used. Uniform definitions were used but the technical methods were not identical $\vec{\omega}$ in all centres. All methods were thoroughly tested and? in regular use, and when it was feasible records were $x$ referred to one centre for confirmatory measurement. $f$ We therefore feel confident that no systematic errorsiv were introduced into the data because of their multi-or centre origin. Selection of patients for the studyo differed between centres and this has resulted in differences in the mean values for some variables. ThisT was not unexpected and there is no reason to believeo that it has influenced the conclusions of the analysis.

The technical methods selected for study were those available at the time the investigation started, which $\overrightarrow{0}$ were thought to be possibly useful for the non-invasive diagnosis of pulmonary arterial hypertension. The variables finally used in the analysis were derivedo mainly from the ECG, chest radiograph, arteria blood gas analysis, and FEV $_{1}$. Measurements from $M_{\mathrm{W}}$ mode echocardiography were used in fibrosingo alveolitis, but an insufficient number were obtainef from patients with chronic obstructive lung disease too be useful. Myocardial scintigraphy with thallium-201 might have contributed had it been available for a larger number of patients.

Several methods were discarded early in the investigation. The orthostatic variation in transfect factor for carbon monoxide, ${ }^{12}$ which had proved valuable in patients with mitral valve disease, was og no use in patients with pulmonary hypertension not associated with a raised pulmonary venous pressure $\frac{3}{3}$ For the same reason perfusion scanning of the lung ${ }^{13}$ had no diagnostic utility. It was technically difficult to standardise both the recording and the subsequents measurement of precordial mechanocardiographie.

Table 3 Results of validation tests using four statistical procedures in patients with chronic obstructive lung disease*

\begin{tabular}{|c|c|c|c|c|c|c|}
\hline \multirow[b]{2}{*}{ Statistical procedure } & \multirow[b]{2}{*}{$n$} & \multicolumn{3}{|c|}{ PAP category predicted } & \multicolumn{2}{|l|}{ Correctly categorised } \\
\hline & & Correct & Falsely high & Falsely low & $P A P \geqslant 30 \mathrm{~mm} \mathrm{Hg}$ & $P A P>19 \mathrm{~mm} \mathrm{Hg}_{\mathrm{C}}$ \\
\hline $\begin{array}{l}\text { Regression (Set II) } \\
\text { Discriminant analysis (Set II) } \\
\text { Non-parametric KS } \\
\text { Non-parametric FET }\end{array}$ & $\begin{array}{l}49 \\
48 \\
53 \\
54\end{array}$ & $\begin{array}{l}59 \cdot 2 \\
50 \cdot 0 \\
60 \cdot 4 \\
48 \cdot 2\end{array}$ & $\begin{array}{l}30 \cdot 6 \\
35 \cdot 4 \\
28 \cdot 3 \\
44 \cdot 4\end{array}$ & $\begin{array}{r}10 \cdot 2 \\
14 \cdot 6 \\
11 \cdot 3 \\
7 \cdot 4\end{array}$ & $\begin{array}{l}83 \cdot 3 \\
72 \cdot 7 \\
76 \cdot 9 \\
76 \cdot 9\end{array}$ & $\begin{array}{l}90 \cdot 3 \\
83 \cdot 9 \\
90 \cdot 9 \\
94 \cdot 1\end{array}$ \\
\hline
\end{tabular}

*The first section shows the percentage of patients whose pulmonary arterial pressure (PAP) category was correctly predicted, and the percentage in whom the prediction was falsely high or low. The second section shows the percentage of patients with a PAP value of $30 \mathrm{~mm} \mathrm{Hg}$ and above and above $19 \mathrm{~mm} \mathrm{Hg}$ who were correctly placed in these pressure categories.

KS-Kolmogoroff-Smirnoff statistic; FET-Fisher's exact test. 
Table 4 Mean values and standard deviations of variables for three categories of pulmonary arterial pressure (PAP, in $\mathrm{mm} \mathrm{Hg}$ ) and coefficients of correlation between each variable and pulmonary arterial mean pressure in patients with diffuse fibrosing alveolitis

\begin{tabular}{|c|c|c|c|c|c|c|c|c|c|c|c|c|}
\hline \multirow[b]{2}{*}{ Variable } & \multirow[b]{2}{*}{ Abbreviation } & \multirow[b]{2}{*}{ Unit } & \multicolumn{3}{|c|}{$P A P \leqq 19$} & \multicolumn{3}{|c|}{$20 \leqq P A P \leqq 29$} & \multicolumn{3}{|c|}{$P A P \geqq 30$} & \multirow{2}{*}{$\begin{array}{l}\text { Correlation } \\
\text { coefficient } \\
(\boldsymbol{r})\end{array}$} \\
\hline & & & $n$ & Mean & $S D$ & $n$ & Mean & $S D$ & $n$ & Mean & $S D$ & \\
\hline $\begin{array}{l}\text { Heart rate } \\
\text { R wave V1 } \\
\text { R wave AVR } \\
\text { S wave V5 } \\
\text { S wave D1 } \\
\text { S wave D2 } \\
\text { S wave D3 } \\
\text { Max height P2 or P3 } \\
\text { Intrinsicoid deflection V1 } \\
\text { RV wall thickness-systolic } \\
\text { RV cavity-diastolic } \\
\text { Depth of A dip } \\
\text { Pre-ejection period } \\
\text { Vital capacity } \\
\text { Forced expiratory volume in } 1 \\
\text { FEV/FVC } \\
\text { Arterial } \mathrm{O}_{2} \text { tension } \\
\text { Arterial CO tension } \\
\text { Haemoglobin concentration } \\
\text { Packed cell volume }\end{array}$ & $\begin{array}{l}\text { HRATE* } \\
\text { RWAVE V1* } \\
\text { RWAVE AVR* } \\
\text { SWAVE V5* } \\
\text { SWAVE D1 } \\
\text { SWAVE D2 } \\
\text { SWAVE D3 } \\
\text { MaxP2P3* } \\
\text { IDV1* } \\
\text { RVWSYST } \\
\text { RVDC } \\
\text { DEPTHA } \\
\text { RPEP } \\
\text { VC* } \\
\text { SFEV } \\
\text { TIFF* } \\
\text { PO }_{2}^{*} \\
\text { PCO }^{*} \\
\text { Hb }^{*} \\
\text { PCV }^{*}\end{array}$ & $\begin{array}{l}\mathrm{min}^{-1} \\
\mathrm{~mm} \\
\mathrm{~mm} \\
\mathrm{~mm} \\
\mathrm{~mm} \\
\mathrm{~mm} \\
\mathrm{~mm} \\
\mathrm{~mm} \\
\mathrm{~ms} \\
\mathrm{~mm} \\
\mathrm{~mm} \\
\mathrm{~mm} \\
\mathrm{msec} \\
\mathrm{cl} \\
\mathrm{cl} \\
\% \\
\mathrm{~mm} \mathrm{Hg} \\
\mathrm{mm} \mathrm{Hg} \\
\mathrm{g} / \mathrm{l} \\
\%\end{array}$ & $\begin{array}{l}33 \\
33 \\
33 \\
33 \\
22 \\
22 \\
22 \\
33 \\
31 \\
15 \\
23 \\
20 \\
19 \\
33 \\
33 \\
33 \\
33 \\
33 \\
33 \\
33\end{array}$ & $\begin{array}{c}78 \cdot 8 \\
2 \cdot 3 \\
0 \cdot 7 \\
2 \cdot 6 \\
1 \cdot 3 \\
1.2 \\
2 \cdot 1 \\
1 \cdot 1 \\
17.7 \\
6 \cdot 8 \\
16 \cdot 0 \\
3 \cdot 7 \\
88 \cdot 3 \\
328 \\
252 \\
77 \cdot 7 \\
73 \cdot 8 \\
37.5 \\
146 \\
43.9\end{array}$ & $\begin{array}{c}14 \cdot 3 \\
1.9 \\
1 \cdot 1 \\
2.3 \\
2.2 \\
1.6 \\
2.7 \\
0.3 \\
7 \cdot 4 \\
1 \cdot 7 \\
5 \cdot 4 \\
1.8 \\
19 \cdot 0 \\
116 \\
82 \\
9 \cdot 7 \\
9 \cdot 7 \\
4.4 \\
15 \\
4.8\end{array}$ & $\begin{array}{l}19 \\
19 \\
19 \\
19 \\
15 \\
15 \\
15 \\
19 \\
19 \\
7 \\
12 \\
11 \\
11 \\
20 \\
20 \\
20 \\
20 \\
20 \\
20 \\
20\end{array}$ & $\begin{array}{c}74 \cdot 8 \\
2.8 \\
1.4 \\
5 \cdot 2 \\
1.7 \\
1.7 \\
3.5 \\
1.3 \\
20.8 \\
7.4 \\
22.5 \\
3.2 \\
97.1 \\
258 \\
197 \\
75.9 \\
68.9 \\
36.9 \\
152 \\
46.1\end{array}$ & $\begin{array}{c}15.6 \\
1.4 \\
1.6 \\
4.5 \\
2.0 \\
1.7 \\
6.0 \\
0.5 \\
11.2 \\
1.9 \\
10.9 \\
1.4 \\
17.3 \\
99 \\
78 \\
8.2 \\
11.6 \\
4.0 \\
18 \\
6.2\end{array}$ & $\begin{array}{r}19 \\
19 \\
19 \\
19 \\
7 \\
7 \\
7 \\
19 \\
19 \\
11 \\
19 \\
17 \\
18 \\
20 \\
20 \\
20 \\
20 \\
20 \\
20 \\
20\end{array}$ & $\begin{array}{c}93.8 \\
4.1 \\
2.5 \\
6.6 \\
4.7 \\
2.6 \\
0.7 \\
1.9 \\
25.3 \\
9.9 \\
24.9 \\
1.4 \\
101.4 \\
252 \\
183 \\
73.4 \\
60.5 \\
41.5 \\
158 \\
50.6\end{array}$ & $\begin{array}{c}17 \cdot 8 \\
3.2 \\
2.6 \\
6 \cdot 1 \\
3 \cdot 5 \\
1.9 \\
1.0 \\
0.8 \\
12.9 \\
1.9 \\
8.9 \\
1.5 \\
15.8 \\
121 \\
95 \\
11.5 \\
8.0 \\
4.8 \\
20 \\
7.0\end{array}$ & $\begin{array}{c}0.35 \\
0.35 \\
0.34 \\
0.36 \\
0.46 \\
0.24 \dagger \\
-0.03 \dagger \\
0.51 \\
0.36 \\
0.55 \\
0.38 \\
-0.57 \\
0.28 \\
-0.20 \dagger \\
-0.25 \\
-0.21 \dagger \\
-0.49 \\
0.32 \\
0.36 \\
0.49\end{array}$ \\
\hline
\end{tabular}

* Variables which with PAP comprise the first data set (see text).

†Does not differ significantly from zero.

traces. "The vectorcardiogram, available in only a few centres, appeared to have no advantage over the conventional ECG. ${ }^{14}$ Measurements of static lung volumes, airways resistance, lung compliance, and transfer factor were available in a small proportion of the patients studied, and were found to have no predictive value.

The correlation coefficients between pulmonary arterial pressure and individual variables were statistically significant, but only a small part of the variance in pulmonary arterial pressure was explained in each case and consequently the variable was of no use as a predictor of pulmonary arterial pressure. The large size of the data set permitted further analysis, including some mathematical procedures less often used for this purpose.

If it had proved possible to use the non-invasive measurements to predict the numerical value of pulmonary arterial pressure with sufficient precision to be practically useful this would have been the preferred approach. When stepwise regression analysis was used in this way the results were similar to those reported previously. The regression equations explained $44 \%$ of the variance in pulmonary arterial pressure. The value in fibrosing alveolitis was higher at $56 \%$ but this was based on a smaller number of patients and is probably less reliable. As a means of prediction the margin of uncertainty was too large for the method to be of practical use. It may be possible in the future, with newer methods, to improve the accuracy of prediction, but for the present analysis we have concentrated on using the data to place an individual into one or other pulmonary arterial pressure category rather than attempt to predict the actual pressure.

Discriminant analysis gave results with a sensitivity of up to $80 \%$ in chronic obstructive lung disease, and with values rather higher in fibrosing alveolitis. The non-parametric procedures allowed greater flexibility. That based on the Kolmogoroff-Smirnoff statistic generally gave results similar to those of the discrimin-

Table 5 Results of stepwise regression analysis using two data sets in patients with diffuse fibrosing alveolitis

\begin{tabular}{|c|c|c|c|c|c|}
\hline \multicolumn{3}{|l|}{$\operatorname{SETI}(n=69)$} & \multicolumn{3}{|l|}{$\operatorname{SETII}(n=35)$} \\
\hline Entered variables & $R^{2} \%$ & $\begin{array}{l}\text { Coefficient of regression } \\
\text { equation }(S E)\end{array}$ & Entered variables & $R^{2} \%$ & $\begin{array}{l}\text { Coefficient of regression } \\
\text { equation (SE) }\end{array}$ \\
\hline $\begin{array}{l}\text { PCV } \\
\text { Max P2P3 } \\
\text { PO }_{2} \\
\mathbf{R}^{2} \text { wave V1 } \\
\text { Intercept }\end{array}$ & $\begin{array}{l}28 \cdot 1 \\
46 \cdot 0 \\
52 \cdot 7 \\
55 \cdot 9\end{array}$ & $\begin{array}{r}0.669(0.142) \\
4.719(1.665) \\
-0.279(0.083) \\
0.917(0.425)\end{array}$ & $\begin{array}{l}\text { PCV } \\
\text { DEPTHA } \\
\text { Hb } \\
\text { IDV } 1 \\
\text { RVDC } \\
\text { Intercept }\end{array}$ & $\begin{array}{l}43 \cdot 6 \\
61 \cdot 7 \\
70 \cdot 3 \\
74 \cdot 0 \\
78 \cdot 2\end{array}$ & $\begin{array}{r}1.750(0.422) \\
-2.236(0.582) \\
-0.358(0.135) \\
0.396(0.134) \\
0.346(0.146) \\
-11.452\end{array}$ \\
\hline
\end{tabular}


ant analysis. The second, based on Fisher's exact test, gave rather better results with sensitivity around $90 \%$. It was especially effective in selecting patients with high pulmonary arterial pressure.

The measurements used to validate the derived functions showed that discriminant function analysis was the least satisfactory method for categorising the newly studied patients. The other methods were about equally reliable in placing the patients in the correct category and had a sensitivity of about $90 \%$ in detecting the presence of pulmonary hypertension. Unfortunately some data were missing and in consequence the derived functions performed less well than they might have done with complete data.

The procedures could be used to screen a population of patients to select those likely to have pulmonary hypertension, who would then undergo cardiac catheterisation. There is a need for a procedure that will reliably select a very high proportion of those with pulmonary arterial hypertension (high sensitivity) and will include only a small number of those with normal pulmonary arterial pressure (high specificity).

Discriminant function analysis has little to offer for this purpose. The non-parametric procedures performed better, and they allow the incorporation of discrete variables, which is sometimes useful. They also permit variables to be selected, their order determined, and the cutting point decided. With experience it may well prove possible to select these to maximise the sensitivity and specificity, and to "tailor" the functions to meet special requirements.

Since the investigation began some promising new methods have become available. With two dimensional echocardiography records may be obtainable in a larger proportion of patients with chronic obstructive lung disease than with $M$ mode echocardiography, and the measurements may be more accurate. In this case measurement of right ventricle cavity dimensions and wall thickness may prove useful. Measurement of blood flow using Doppler echocardiography has yet to be thoroughly explored in chronic respiratory disease.

In this study we have concentrated on predicting the presence and degree of pulmonary arterial hypertension. Some but not all of the measured variables are thought to reflect aspects of right ventricular structure and function. Although pulmonary arterial hypertension, right ventricular hypertrophy, and subsequently right ventricular failure are closely related, we need to understand more about the time course of the progression from one to the other-whether, for example, pulmonary arterial hypertension can be identified at an early stage before right ventricular hypertrophy has developed.

Our results confirm that no single variable that we tested provides a non-invasive procedure capable of measuring pulmonary arterial pressure sufficiently accurately to be useful. We have shown the potential of mathematical functions that combine the results from simple, readily available, and relatively cheap methods for detecting pulmonary hypertension. We have described how these functions can be used in their present form by anyone interested in screening a population of individuals at risk of pulmonary hypertension. Possible populations for screening could include patients with chronic bronchitis, an occupational group, and patients taking a particular drug.

We have described how the mathematical functions have been derived and we emphasise that as other noninvasive methods become available the results can be incorporated into new functions, whose value can be tested. It will also be possible to refine the functions further, and to adjust the specificity and sensitivity according to the requirements of a particular investigation.

\section{Appendix}

We wished to classify subjects into one of three groups $\vec{\oplus}$ according to their pulmonary arterial pressure by means of 6 other, so called explanatory, variables provided by the results of a series of non-invasive diagnostic tests. This problem may be approached by different methods, including linear discriminant analysis, which assumes a normal distribution of the values of the explanatory variables, and non-parametric methods, where no such assumption is required. The latter also permit the use of discrete (non-continuous) variables. We provide here a brief description of the procedures we have used and a demonstration of their application.

\section{LINEAR DISCRIMINANT ANALYSIS}

Linear discriminant analysis requires a linear function of the explanatory variables. The coefficients of this function are computed from the empirical covariance matrix of the PAP and the explanatory variables. As an example the function for discriminating between groups of patients with chronic obstructive lung disease with a pulmonary artery pressure of $29 \mathrm{~mm} \mathrm{Hg}$ or less and of $30 \mathrm{~mm} \mathrm{Hg}$ or more is $y=0.408$ (SWAVEVI) $-0.066\left(\mathrm{Po}_{2}\right)-0.011(\mathrm{pH})+7.559$. The known values for the variables are entered; if $y$ is greater than zero the patient is put in the group pulmonary arterial pressure (PAP) $\geqslant 30$ and otherwise into the group PAP $\leqslant 29$. By another function and a similar procedure the patients may be $\mathrm{N}$ classified as PAP $\geqslant 20$ and PAP $\leqslant 19$.

NON-PARAMETRIC DECISION PROCEDURE BASED ON THE KOLMOGOROFF-SMIRNOFF TEST

The Kolmogoroff-Smirnoff (K-S) statistic ${ }^{17-19}$ is the maximum value of the difference between the empirical distributions of random variables drawn from two samples. We have used the K-S statistic to separate patients into two groups according to their pulmonary arterial pressure. The value of a given explanatory variable at which the maximum difference was reached was used as a cutting point to classify patients according to this grouping.

We have applied the method in a stepwise way, and to 
illustrate the procedure we describe here (fig 1 ) the subdivision of patients with chronic obstructive lung disease into the groups PAP $\geqslant 30$ and PAP $\leqslant 29$. Firstly, the variable for which the K-S statistic is maximal is selected; in this example it is SWAVEDl, and the cutting point is 1 . At the second step the same procedure has been used separately for the two groups obtained at the first step. For the group in whom SWAVEDl is $\leqslant 1$ the K-S statistic was maximal for pulmonary arterial diameter (PAD), with a cutting point of 20. For the other group obtained at the first step, in whom SWAVEDl is $>1$, the appropriate variable at the second stage was $\mathrm{PCO}_{2}$ with a cutting value of $47 \mathrm{~mm} \mathrm{Hg} \mathrm{(6.3} \mathrm{kPa})$.

The stepwise application of the K-S statistic enables the rate of misclassification to be progressively diminished. In practice we found that there was no further improvement after two or three steps. Patients for whom a value for the variable required at a particular stage was missing were eliminated at that stage. Figures 1 and 2 show the decision trees for PAP $\leqslant 29$ and PAP $\geqslant 30$ and for PAP $\leqslant 19$ and $\geqslant 20$. The values for a patient are entered into both figures, so that the patient is classified according to PAP groupnamely, PAP $\leqslant 19$, PAP $=20-29$, or PAP $\geqslant 30$. Three patients were classified as both PAP $\leqslant 19$ and PAP $\geqslant 30$.

NON-PARAMETRIC DECISION PROCEDURE BASED ON FISHER'S EXACT TEST

This is a two stage procedure which classifies the patients in the three PAP categories used in the previous procedure. The first stage aims to select out those patients with PAP $\geqslant 30$ while minimising any misclassification. The aim is for the selected group to contain as large a proportion as possible of those patients with a true PAP $\geqslant 30$, and as few as possible of those with PAP $\leqslant 29$. In the second stage the patients not classified into the PAP $\geqslant 30$ group are treated in a similar manner. This time the aim is to select those patients with PAP $\leqslant 19$ with a minimum of misclassification.

The construction of the decision graphs is based upon general principles previously developed. ${ }^{20}{ }^{21}$ The method we have developed differs somewhat in that we construct more general graphs. It uses Fisher's exact probability test, ${ }^{23}$ and a detailed description is given elsewhere. ${ }^{22}$

Examples of the decision graphs for patients with chronic obstructive lung disease are given in figures 3 and 4 . In essence the method requires, at the first step, the selection of a variable and a threshold value for that variable. Patients are classified at the threshold value in group 1 (for example, PAP $\geqslant 30$ ) or group 2 (PAP $\leqslant 29$ ). If the probability of the allocation to group 1 exceeds a predetermined value then the patient is finally classified in group 1 (labelled F). For the remainder a new variable and threshold are selected in the same way and the process repeated. If a value is missing at any step the patient is classified in the group not under selection (group 2). The number of steps is variable and may be limited to a preset number, or when further variables fail to classify more patients to $F$. It will be evident that in the most extreme case a patient with a true PAP $\geqslant 30$ might be classified to the group PAP $\leqslant 19$. Such misclassification occurred in only two patients.

\section{References}

1 Enson Y, Giuntini C, Lewis ML, Morris TQ, Ferrer MI, Harvey RM. The influence of hydrogen ion concentration and hypoxia on the pulmonary circulation. $J$ Clin Invest 1964;43:1146-62.

2 Lockhart A, Pham QT, Nakache JP, Salmon D, Perrault J. Pression arterielle pulmonaire dans la bronchite chronique bien compensée: étude par l'analyse factorielle des correspondances. Bull Physiopathol Respir 1969;5:347-61.

3 Simon H, Fink H, Fricke G, Ferlinz R, Kikis D. Einfluss der Blutgaspartialdrucke und der Lungfunktionsparameter auf den Pulmonalarterienmitteldruck beim obstruktiven Syndrom. Klin Wochenschr 1973;51: 562-4.

4 Rizzato GF, Rampulla C, Mandelli V, Benza GC, Mantero O, Morpurgo M. Can pulmonary artery pressure be predicted without right heart catheterisation in chronic obstructive lung disease? Acta Cardiol 1975;30:251-65.

5 Bishop JM, Cross KW. Use of other physiological variables to predict pulmonary artery pressure in patients with chronic respiratory disease. Eur Heart J 1981;2:509-17.

6 Tartulier M, Greiner O, Tartulier G, Boutarin J. Noninvasive diagnosis of pulmonary arterial hypertension in chronic obstructive lung disease. Progr Respir Res 1985;20:126-35.

7 Evers H, Liehs F. Vohersage der pulmonalen Hypertonie aus einfachen, nicht invasiven Parametern unter Verwendung der Diskriminalyse. Z Erkrank Atm Org 1985;164:284-7.

8 Keller CA, Shepard JW, Chun DS, Vasquez P, Dolan GF. Pulmonary hypertension in chronic obstructive pulmonary disease; multivariate analysis. Chest 1986;90:185-92.

9 Oswald-Mammosser M, Oswald T, Nyankiye E, et al. Non-invasive diagnosis of pulmonary hypertension in chronic obstructive pulmonary disease: comparison of ECG, radiological measurements, echocardiography and myocardial scintigraphy. Eur J Respir Dis 1987; 71:419-29.

10 Weitzenblum E, Moyses B, Dickele MC, Methlin G. Detection of right ventricular pressure overloading by thallium-201 myocardial scintigraphy. Chest 1984; 85:164-9.

11 Morpurgo $M$. Non-invasive methods for the assessment of pulmonary arterial hypertension. Medicina Toracina 1981;3:263-8.

12 Widimsky J, Tartulier M, Zielinski J, Fridl P. Prediction of pulmonary hypertension from postural changes of pulmonary transfer factor. Respiration 1984;46:241-5.

13 Weitzenblum E, Moyses B, Methlin G. Relationship between pulmonary artery mean pressure and the vertical gradient of perfusion in chronic respiratory diseases. Respiration 1984;46:337-41.

14 Bottoni R, Mandelli V, Marzegalli M, Moccetti T, Morpurgo M. Predettività dei criteri elettrocardiografici e vettorcardiografici nell' ipertensione arteriosa polmonare da bronchopneumopatie croniche. G Ital Cardiol 1979;9:390-9. 
15 Hicken P,Green ID, Bishop JM. Relationship between transpulmonary artery distance and pulmonary arterial pressure in patients with chronic bronchitis. Thorax 1968;23:446-50.

16 Morbelli E, Balzaretti G, Regalia F, Delli Santi N, Morpurgo M. Diametro dell'arteria lobare inferiore destra come indice di ipertensione arteriosa polmonare. Misura xerotomografica. Giornale di Clinica $e$ Fisiopatologia Cardiovascolare 1984;3:43-8.

17 Kolmogoroff AN. Sulla determinazione di una legge di distribuzione. Giornale dell'Istituto Italiano degli Attuari 1933;4:83-91.

18 Smirnoff NV. Uber die Verteilung allgemeinen Gliedes in der Variationsreihe. Metron 1935;12:59-81.
19 Rosenblatt I. Some modified Kolmogorov-Smirnoff tests of approximate hypothesis and their properties. Annals of Mathematical Statistics 1962;33:513-24.

20 Brieman L, Friedman JH, Olshen RA, Stone CJ. Classification and regression trees. California: Wadsworth International, 1984.

21 Marshall RJ. Partitioning methods for classification and decision making in medicine. Statistics in Medicine 1986;5:517-26.

22 Csukas M, Kramli A, Soltesz J. Sequential methods in medical decision making. In: Carson ER, ed. Advances in biomedical measurement. New York: Plenum, 1988.

23 Armitage P. Statistical methods in medical research. Oxford: Blackwell, 1973. 